\title{
Ergonomics Job Hazard Evaluation of Building Cleaners
}

\author{
Kyung-Sun Lee ${ }^{1}$, Inseok Lee ${ }^{2}$, Hyunjoo Kim ${ }^{3}$, Kyunghee Jung-Choi ${ }^{4}$, \\ Jinwook Bahk ${ }^{5}$, Myung-Chul Jung ${ }^{1}$ \\ ${ }^{1}$ Department of Industrial and Information Systems Engineering, Ajou University, Suwon, 443-749 \\ ${ }^{2}$ Department of Safety Engineering, Hankyong National University, Anseong, 456-749 \\ ${ }^{3}$ Department of Occupational and Environmental Medicine, Dankook University College of Medicine, Cheonan, 330-714 \\ ${ }^{4}$ Department of Preventive Medicine, Ewha Womans University School of Medicine, Seoul, 120-750 \\ ${ }^{5}$ School of Public Health, Seoul National University, Seoul, 151-742
}

\begin{abstract}
Objective: The objective of this study was to evaluate a work of building cleaners using the ergonomic methods. Background: Previous studies about cleaning worker describe typical physical demands of this work. They found that the most significant risk factors associated with the physical work of cleaners are static loads and repetitive movements and high output of force. Method: A head of ergonomics estimation was work analysis(define of combined task, work tool, work time and frequency of combined task) and posture analysis of worker. Results: The results showed that combined task of building cleaners was classification sweeping, mopping(wet), mopping(oil), moving barrels/carts, dumping trash bags, scrubbing, arrangement of cleaning tool, arrangement of circumferential, moving of cleaning tool, and waiting. The work time of combined task such as mopping(wet) and scrubbing indicated high ratio. The posture analysis of building cleaners indicated high value in bending of the head, lower arm, and hands. Conclusion: The findings appear to indicate that building cleaner were related to high risk of work-related musculoskeletal disorders. So, building cleaner would be required an interventional strategy, improvement of cleaning tools and working environment. Application: If ergonomics rule can be integrated into existing cleaning tools and work environments, the risk of occupational injuries will be reduced.
\end{abstract}

Keywords: Musculoskeletal symptoms, Building Cleaners, Work Analysis, Posture Analysis

\section{Introduction}

최근 5 년간 산재통계 분석 결과, 서비스 업종에서 근골 격계질환 요양자수 및 구성 비율이 해마다 증가하고 있다. 2004년 서비스업 근골격계 요양자수는 581명 이었으나, 2008년에는 2,559명으로 약 5 배 가량 증가하였다(Korea Ministry of Labor, 2004 2008).

서비스 업종 작업자의 인구학적 특성을 보면 고령 작업자 가 높은 비중을 차지하고 있다. 고령 취업자의 주요 취업 직종은 상점 판매 및 관리인이 가장 많았고, 청소원, 경비
및 건물관리인 순이었다(Korea Employment Information Service, 2004). Park and Jung(2008)은 50세 이상 고 령 작업자의 근골격계질환은 2000년 $13.5 \%$ 에서 2007년 $23.6 \%$ 로 지난 7년간 $10.1 \%$ 증가하였으며, 2026년에는 50 세 이상 고령 작업자가 전체 근골격계질환자수의 $42.5 \%$ 를 차지하게 될 거라는 예측을 하며 고령자의 근골격계질환의 심각성에 대하여 언급하였다.

이처럼, 서비스업과 고령 작업자에서 근골격계질환 요양자 수는 높아지고 있는 실정이다. 하지만 고령 작업자의 주요 취업 직종인 서비스 업종은 근골격계질환 요인 파악 및 예 방을 위한 연구가 현재 부족한 상태이다. 다양한 서비스업

Corresponding Author: Myung-Chul Jung. Department of Industrial and Information Systems Engineering, Ajou University, Suwon, 443-749.

Phone: 031-219-2981, E-mail: mcjung@ajou.ac.kr

Copyright@2011 by Ergonomics Society of Korea(pISSN:1229-1684 eISSN:2093-8462). All right reserved. 
중에서 특히 청소직은 대부분이 고령의 여성이 많이 분포하 고 있다(WHO, 1993).

사무실, 상점, 아파트, 호텔 등과 같은 건물에서의 청소는 먼지 털기, 대걸레질, 손걸레질, 쓸기, 진공 청소 등의 작 업으로 이루어 진다(Kumar and Kumar, 2008). Nielsen (1995)은 건물청소직 작업이 근골격계질환의 위험이 높은 작업이라고 하였으며, Hagner and Hagberg(1989) 또한 건물청소직 작업은 신체적인 활동의 요구가 높다고 하였다. Huth et al.(1996)은 병원 청소 작업자의 $90 \%$ 가 작업에 어려움을 느끼며, $62.4 \%$ 가 할당된 작업을 제대로 완료하기 위한 작업시간이 부적절했다고 보고하였다. Kumar and $\operatorname{Kumar}$ (2008)은 청소직 작업은 무리한 힘, 반복동작, 정적 자세의 위험한 요인을 지니고 있다고 하였으며, 몇몇 연구 자들은 청소 작업을 할 때 심혈관(Cardiovascular)의 부하 가 크고 부적절한 자세가 반복적으로 발생한다는 결과를 제 시하였다(Messing et al., 1992; Kumar et al., 2005; Woods and Buckle, 2005). 이처럼 여러 연구자들이 청소 작업은 힘이 많이 드는(Strenuous) 작업이라고 설명한다.

Hopsu et al.(1994)의 연구에서 청소 작업은 정적(Static) 과 동적(Dynamic)인 근육 운동이 모두 필요한 어려운 작업 이라고 언급하였다. Johansson and Ljunggren(1989)는 청소직 작업자를 대상으로 주관적 설문지(Borg's Scale) 와 심박수(Heart Rate) 측정 방법을 사용하여 작업의 강도를 평가하였다. 그 결과, 대부분의 작업자가 주관적으로 작업의 어려움을 느끼고 있으며, 작업자가 보통 작업을 하고 있을 때 작업자의 최대산소섭취량 (maximal oxygen uptake) 의 약 $35 \%$ 에 대응하는 결과를 나타냈다. Hagner and Hagberg (1989)는 마루 걸레를 사용한 바닥 청소 작업 중 8자 유형의 걸레질과 밀기 유형의 걸레질을 주관적 설문지, 근전도와 심전도를 평가한 결과, 밀기 유형의 걸레질 방법 이 불편도와 근육 부하가 낮다는 결과를 제시하였다. 이처 럼 선행 연구들은 청소 방법과 작업 자세에 대하여 생리학 (Physiological), 생체역학(Biomechanical), 그리고 심리사 회적(Psychosocial) 측면으로 분석하였다.

청소직은 근골격계질환의 위험성이 높은 직종으로 외국에 서는 다수의 연구자에 의하여 활발하게 연구가 진행되어 왔 다. 하지만 국내에서는 Lee et al. (2007) 과 Myong et al. (2008)이 환경미화원의 근골격계질환 자각증상 특성과 인 간공학적 평가를 수행한 연구를 제외하고 건물청소직에 대 한 연구를 찾아보기 힘들다. 또한 국외의 연구들은 사용장비, 근무조건, 작업환경, 작업자의 신체특성이 국내의 작업자와 차이를 나타내기 때문에 국내에 적용하기에는 어려움이 따 른다. 또한 대부분의 연구가 걸레질과 쓸기 작업과 같은 한 정된 작업에 대하여만 평가가 이루어지고 있다. 또한 건물청 소직은 비정형인 작업임에도 불구하고 제조업의 분석과 같
은 샘플링 기법들을 사용하여 작업시간과 자세를 분석한다 는 문제점이 있다.

따라서 본 연구의 목적은 건물청소 작업자에 대하여 동영 상 분석을 기반으로 작업분석, 자세분석을 실시하여, 작업자 의 작업특성과 유해요인을 분석하는 것이다.

\section{Method}

\subsection{Research subjects}

연구대상은 충청도 소재의 대학병원과 아파트, 경기도 소 재의 대학교에 근무하는 건물청소직 작업자 각각 2 명씩, 총 6 명을 대상으로 하였다. 연구대상자는 모두 여성으로 평균 연령은 $61.0( \pm 5.1)$ 세이며, 키는 $156.2( \pm 6.3) \mathrm{cm}$, 그리고 몸무게는 $55.7( \pm 4.0) \mathrm{kg}$ 이었다. 건물청소직 작업자에 대한 분석은 2009년 7월부터 8월까지 사업주의 협조를 얻어 수 행되었다.

\subsection{Research methods}

건물청소 작업에 대한 인간공학적 평가는 크게 작업분석 과 자세분석을 실시하였다. 작업분석을 통하여 먼저 건물청 소 작업에 대한 단위 작업을 정의하고 작업도구 및 작업대 분석, 평균작업시간 및 하루 동안의 총 작업시간을 산출하였 다. 마지막으로, 자세분석을 통하여 단위 작업에서 가장 빈 번히 발생하는 자세를 얻어내며, 상체 자세에 있어서는 부적 절한 자세가 가장 많이 발생한 체절을 분석하였다.

\subsubsection{Work analysis}

작업 현장의 비디오 촬영은 청소 작업자가 청소를 시작하 기 위한 준비 작업부터 종료가 되는 시점까지 진행하였다. 작업자는 가능한 카메라를 의식하지 않고 작업에 임하도록 교육을 실시하였으며, 관찰자 역시 작업자의 작업에 방해가 되지 않도록 촬영을 실시하였다. 비디오 촬영은 작업자의 전 신과 작업반경이 모두 촬영되도록 하였으며, 이동 작업 시에 는 관찰자 역시 함께 이동하며 촬영에 임하였다.

단위 작업 정의는 작업자 인터뷰와 현장 조사 동안 디지털 캠코더로 촬영된 동영상 자료를 기반으로 관찰자 간의 협의 를 통하여 정의하였다. 작업도구 및 작업대 분석은 작업 중 사용하는 작업도구에 관하여 치수정보를 수집하였다. 각 단 위 작업의 평균작업시간은 각각의 작업자에게 촬영된 동영 상 시간 중에 발생하는 단위 작업의 시간을 산출하였다. 쵤 영된 동영상에 의해 산출된 단위 작업시간은 하루 8시간 기 준 단위 작업별 작업시간으로 환산하였다(식 1 ). 즉, 촬영을 
통해 얻은 총작업시간 대비 평균단위 작업시간의 비율을 고 려하여 하루 근무시간인 480 분 대비 환산작업시간의 값을 계산하였다.

$$
\text { 환산작업시간 }(\text { 분 })=\frac{480 \text { 분 } \times \text { 평균단위 작업시간(분) }}{\text { 총작업시간 }(\text { 분 })} \text { 식 (1) }
$$

\subsubsection{Posture analysis}

자세분석에 사용하는 샘플의 선정은 촬영된 동영상을 편 집하여 추출된 단위 작업별 샘플들 중에서 가장 에러(가 림현상, 동영상 촬영상태)가 적다고 판단되는 샘플 1 개를 대표로 선정하였다. 자세 분류는 Ovako working posture analyzing system(OWA)S의 macro 자세분석 방식을 고 려하였으며 이는 하루 중 일어나는 자세들에 대한 직관적 인 이해가 가능하다(Karhu et al., 1977). 상체 자세분석은 목, 위팔, 아래팔, 손, 허리에 대하여 중립, 굴곡, 회전, 판 단불가(가림현상)의 항목으로 구분하여 분석하였다. 위팔 굴곡은 $90^{\circ}$ 이상 그리고 $90^{\circ}$ 이하로 (Keyserling, 1986; $1992)$ 구분하였으며, 허리는 $45^{\circ}$ 이상과 $45^{\circ}$ 이하로 구분 하였다(Froeman and Troup, 1987; Genaidy et al., 1993). 손, 목 그리고 아래팔 굴곡은 중립 자세 $\left(0^{\circ}\right.$ 또는 직선)를 기준으로 평가하였다. 하지는 Lee et al. (2002), Baty et al. (1987), Grandjean et al. (1977), Keyserling (1990) 그리 고 Ryan(1989)의 연구를 기초로 서기, 무릎굽혀서기, 걷기, 앉기, 기타, 판단불가(가림현상) 항목으로 구분하여 분석하 였다(Table 1). 서기와 걷기의 경우 전후 프레임을 관찰하 여 자세를 구분하였으며 세 발자국 이상 지면을 밞을 시 걷

Table 1. Posture analysis criteria

\begin{tabular}{l|l|l}
\hline Body & Classification & \multicolumn{1}{c}{ Criteria } \\
\hline \multirow{4}{*}{$\begin{array}{l}\text { Upper } \\
\text { ody }\end{array}$} & Neck & $0^{\circ}$ or Straight \\
\cline { 2 - 3 } & Upper arm & Below $90^{\circ}$, More than $90^{\circ}$ \\
\cline { 2 - 3 } & Lower arm & $0^{\circ}$ or Straight \\
\cline { 2 - 3 } & Hand & $0^{\circ}$ or Straight \\
\cline { 2 - 3 } & Trunk & Below $45^{\circ}$, More than $45^{\circ}$ \\
\hline \multirow{4}{*}{$\begin{array}{l}\text { Lower } \\
\text { body }\end{array}$} & Standing & Feet are only supported by the ground \\
\cline { 2 - 3 } & $\begin{array}{l}\text { Standing with } \\
\text { bending knee }\end{array}$ & $\begin{array}{l}\text { Feet are supported by the ground } \\
\text { with bending knee }\end{array}$ \\
\cline { 2 - 3 } & Walking & Walking more than two steps \\
\cline { 2 - 3 } & Leaning & $\begin{array}{l}\text { Part of the body mass is supported by } \\
\text { the external object }\end{array}$ \\
\cline { 2 - 3 } & Sitting & $\begin{array}{l}\text { Body mass is mainly supported by } \\
\text { ischial tuberosity }\end{array}$ \\
\cline { 2 - 3 } & Etc. & Kneeling or squatting \\
\hline
\end{tabular}

기로 정의하였다. 대기는 작업자들의 상체 움직임이 거의 없 다고 가정하고 하지의 자세만 분석항목에 포함하였다.

자세분석은 분석자간의 에러를 방지하기 위하여 한 명의 숙련된 분석자가 분석을 실시하였으며, 자세분석의 분석주기 는 1 초에 1 프레임 간격으로 하였다(Andrews and Callaghan, 2003). 자료의 분석과 편집은 Adobe Premiere V6를 사용 하였다.

\section{Results}

\subsection{Work analysis}

건물청소직 작업자는 월 평균 24.4 일을 근무하며, 주당 평균 노동시간은 44.3 시간이었다. 일반적으로, 하루 8 시간 근무로서 점심시간은 약 1 시간 가량이며 정해진 휴식시간 없이 작업자 재량으로 각자 휴식을 취하였다. 건물청소직 작 업자는 건물내부의 복도, 화장실, 강의실, 사무실, 병실, 계단 등에서 발생하는 쓰레기를 청소하고 정리하는 업무를 주로 하며 건물의 내벽, 창틀, 세면대 등을 닦거나 분리수거를 하 기도 하였다.

건물청소직 작업자들의 작업분석을 통하여, 빗자루 청 소(Sweeping), 물걸레질 (Mopping(Wet)), 기름걸레질 (Mopping(Oil)), 쓰레기 비우기(Dumping trash bags), 쓰

Table 2. Combined task of building cleaners

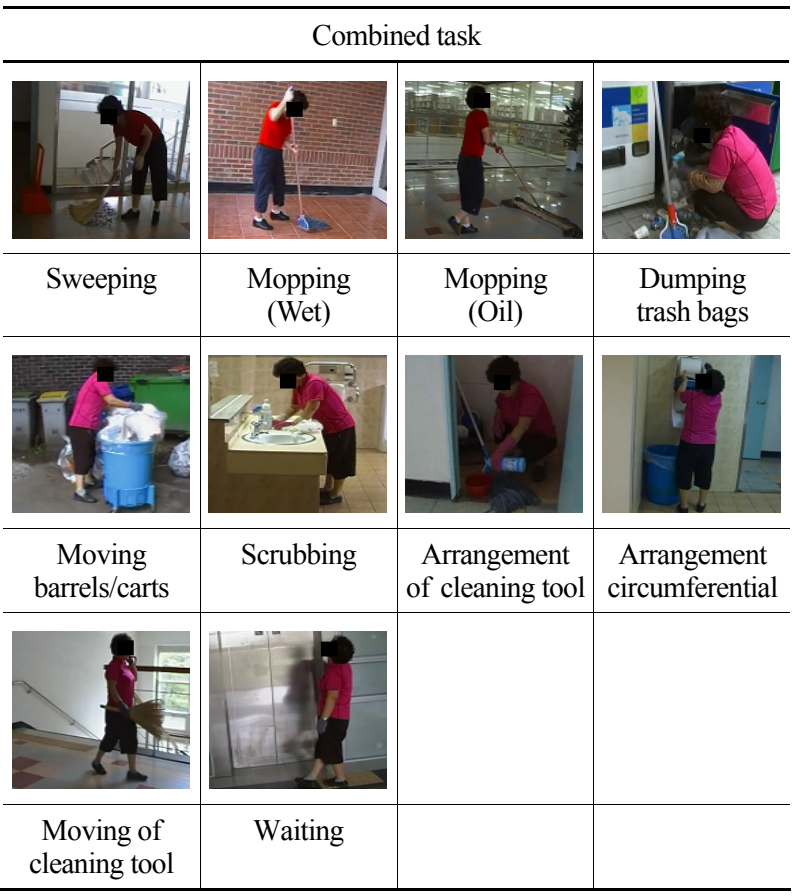


레기 버리기(Moving barrels/carts), 닦기(Scrubbing), 청 소도구 정리 (Arrangement of cleaning tool), 주변 정리 (Arrangement circumferential), 청소도구 운반(Moving of cleaning tool), 대기(Waiting)로서 총 10 가지 단위 작업을 구분하였다(Table 2).

빗자루 청소 작업은 빗자루(총길이: $86 \mathrm{~cm}$, 손잡이둘레: $12 \mathrm{~cm}$, 무게: $0.2 \mathrm{~kg}$ )를 사용하여, 복도, 계단, 화장실, 병실, 강의실, 사무실 바닥의 쓰레기들을 쓸어 모아 쓰레받기(총 길이: $66.5 \mathrm{~cm}$, 깊이: $35 \mathrm{~cm}$, 손잡이둘레: $9 \mathrm{~cm}$, 무게: $1.5 \mathrm{~kg}$ ) 에 쓸어 담는 작업이다. 단위 작업의 시점은 작업자가 빗자 루를 들고 청소를 시작하는 순간으로 정의하였다. 물걸레질 작업은 물에 젖은 대걸레(총길이 $153 \mathrm{~cm}$, 손잡이둘레 $9 \mathrm{~cm}$, 무게: $3.1 \mathrm{~kg}$ )를 이용하여 바닥의 얼룩과 먼지를 제거하는 작업이다. 단위 작업의 시점은 작업자가 대걸레를 들고 청소 를 시작하는 순간으로 정의하였다.

기름걸레질 작업은 물걸레질 작업과 비슷하게 기름대걸 레(총길이 $140 \mathrm{~cm}$, 너비 $90 \mathrm{~cm}$, 손잡이둘레 $9.8 \mathrm{~cm}$, 무게: $4.3 \mathrm{~kg}$ ) 를 이용하여 건물 내 바닥을 매끄럽고 윤이 나게 하 기 위한 작업이다. 단위 작업의 시점은 작업자가 기름걸레를 사용하여 걸레질을 시작하는 순간으로 정의하였다.

쓰레기 비우기 작업은 각 장소에 비치된 쓰레기통 내부의 쓰레기를 꺼내어 비우는 작업이다. 쓰레기 버리기 작업은 쓰 레기 비우기 작업 후 이동 카트(총길이 $73 \mathrm{~cm}$, 지름 $50 \mathrm{~cm}$, 바퀴지름 $8 \mathrm{~cm}$, 무게: $5.0 \mathrm{~g}$ ) 를 사용하여 쓰레기봉투를 소각 장이나 쓰레기 수거장으로 버리는 작업이다. 단위 작업의 시 점은 작업자가 쓰레기를 비우기 위하여 쓰레기통을 잡는 순 간으로 정의하였다. 닦기 작업은 손걸레, 수세미를 이용하여 화장실의 세면대 및 대· 소변기, 유리창, 창틀, 계단 난관을 닦는 모든 작업을 말한다. 단위 작업의 시점은 작업자가 손 걸레나 수세미를 사용해 청소를 시작하는 순간으로 정의하 였다.

청소도구 정리 작업은 사용한 대걸레, 기름걸레, 손걸레를 빨거나 털어내어 창고 내에 정리하는 작업이다. 단위 작업의 시점은 작업자가 청소도구를 들어 창고 내에 놓는 순간으로 정의하였다. 주변 정리 작업은 청소하는 업무 외에 쓰레기통, 정수기, 강의실 책상, 의자 등을 정리하는 작업이다. 단위 작 업의 시점은 작업자가 물픔들을 정리하기 시작하는 순간으 로 정의하였다. 청소도구 운반 작업은 청소를 마친 후 혹은 청소를 하기 위해 청소관련 도구를 운반하는 작업이다. 단위 작업의 시점은 작업자가 청소관련 도구를 잡고 걷기 시작하 는 순간으로 정의하였다. 작업은 위의 정의된 단위 작업 외 의 작업과 관련 없는 동작을 의미한다. 건물청소직 작업자의 주 사용 작업도구는 Table 3 과 같다.

현장 조사 시 촬영한 녹화시간은 각각 265 분(작업자 1 ), 200 분(작업자 2), 275분(작업자 3), 286 분(작업자 4),
Table 3. Tool of building cleaner

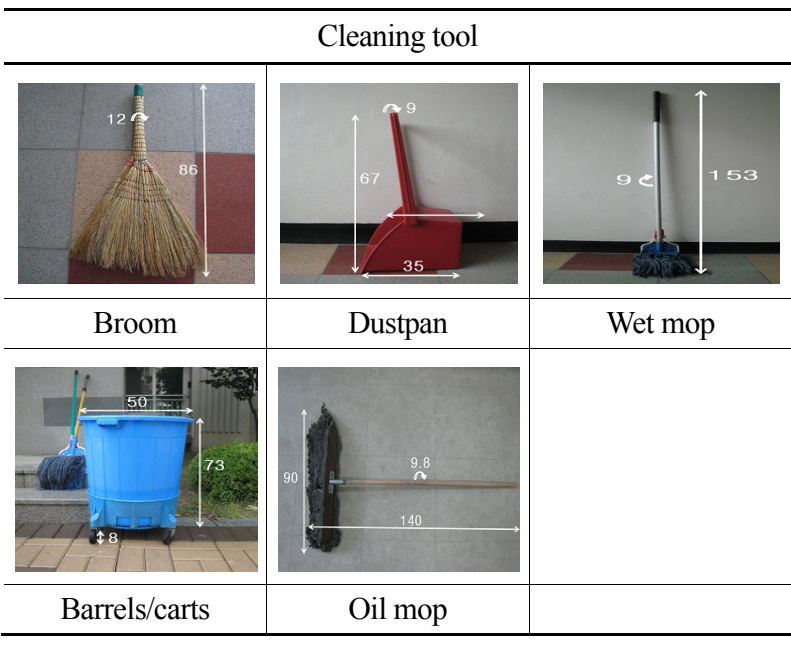

309분(작업자 5), 231분(작업자 6)이다.

Table 4는 촬영된 동영상에 대한 단위 작업별 작업시간 (분) 과 작업빈도(횟수)를 산출하고 이를 식 1을 사용하여 하루 8시간 기준으로 단위 작업별 작업시간(분)과 작업빈 도(횟수)를 작업자 별로 나타낸 것이다. 여기서 작업시간은 단위 작업의 지속시간을 의미하며 작업빈도는 단위 작업의 발생 횟수를 의미하였다. 단위 작업별 작업빈도 및 시간을 살펴보면, 빗자루 청소 작업은 하루 43.8분 동안 총 27.9회 이루어진다. 물걸레질은 하루 111.1 분 동안 총 38.9 회가 이루어지며, 기름걸레질은 32.3 분 동안 7.7 회 가량 이루어 진다. 쓰레기 비우기 작업은 하루 작업시간 중 25.4분 동안 13.8 회 발생하며, 쓰레기 버리기 작업은 23.5분 동안 약 10.1 회 발생하였다. 닦기 작업은 93.0분 동안 32.2회 발생 하였으며, 청소도구 정리 작업은 61.0 분 동안 45.4회 발생 한다. 주변 정리 작업은 하루 작업시간 중 9.5분 동안 20.2 회 발생한다. 청소도구 운반 작업은 하루 작업시간 중 34.4 분 동안 43.2 회 발생하며, 대기는 하루 작업시간 중 46.0 분 발생한다.

\subsection{Posture analysis}

선정된 샘플 영상을 통하여 단위 작업의 자세를 분석하였 다. 건물청소직 작업자의 자세분석 샘플 평균(표준편차) 시 간은 빗자루 청소 59.3( \pm 40.0$)$ 초, 물걸레질 68.2( \pm 12.4$)$, 기름걸레질 235.3( \pm 208.2$)$, 쓰레기 비우기 53.2( \pm 10.3$)$, 쓰레기 버리기 144.8( \pm 123.7$)$, 닦기 94.3( \pm 31.9$)$, 청소 도구 정리 61.2( \pm 38.4$)$, 주변 정리 30.2( \pm 22.0$)$, 청소도 구 운반 37.0 ( \pm 20.6$)$ 이다.

Table 5 는 6 명의 작업자 자세분석을 통하여 도출된 환산 
Table 4. Work time(min) and frequency(number) of combined task

\begin{tabular}{|c|c|c|c|c|c|c|c|c|c|c|c|c|c|c|}
\hline \multirow{2}{*}{ Combined task } & \multicolumn{2}{|c|}{ Worker 1} & \multicolumn{2}{|c|}{ Worker 2} & \multicolumn{2}{|c|}{ Worker 3} & \multicolumn{2}{|c|}{ Worker 4} & \multicolumn{2}{|c|}{ Worker 5} & \multicolumn{2}{|c|}{ Worker 6} & \multicolumn{2}{|c|}{ Mean(SD) } \\
\hline & $\mathrm{F}$ & $\mathrm{T}$ & $\mathrm{F}$ & $\mathrm{T}$ & $\mathrm{F}$ & $\mathrm{T}$ & $\mathrm{F}$ & $\mathrm{T}$ & $\mathrm{F}$ & $\mathrm{T}$ & $\mathrm{F}$ & $\mathrm{T}$ & $\mathrm{F}$ & $\mathrm{T}$ \\
\hline Sweeping & 16 & 13 & 4 & 3 & 15 & 23 & 15 & 53 & 26 & 24 & 15 & 27 & $27.9(10.8)$ & $43.8(27.8)$ \\
\hline Mopping(Wet) & 30 & 73 & 24 & 73 & 31 & 69 & 11 & 42 & 20 & 77 & 11 & 29 & $38.9(17.4)$ & $111.1(42.0)$ \\
\hline Mopping(Oil) & 2 & 7 & 1 & 8 & 0 & 0 & 11 & 46 & 4 & 11 & 7 & 32 & $7.7(7.3)$ & $32.3(32.0)$ \\
\hline Dumping Trash Bags & 16 & 32 & 12 & 10 & 2 & 1 & 5 & 7 & 1 & 0 & 9 & 12 & $13.8(12.3)$ & $25.4(21.5)$ \\
\hline Moving barrels/carts & 10 & 16 & 6 & 3 & 4 & 4 & 2 & 13 & 3 & 5 & 8 & 36 & $10.1(6.4)$ & $23.5(26.5)$ \\
\hline Scrubbing & 11 & 51 & 19 & 46 & 8 & 58 & 7 & 61 & 47 & 62 & 13 & 27 & $32.2(25.3)$ & 93.0(19.6) \\
\hline Arrangement of cleaning tool & 17 & 28 & 27 & 28 & 34 & 49 & 18 & 26 & 27 & 45 & 25 & 22 & $45.4(14.4)$ & $61.0(17.2)$ \\
\hline Arrangement circumferential & 8 & 3 & 10 & 5 & 18 & 2 & 2 & 1 & 16 & 5 & 12 & 15 & $20.2(10.2)$ & $9.5(10.8)$ \\
\hline Moving of cleaning tool & 47 & 24 & 13 & 5 & 52 & 56 & 3 & 1 & 19 & 19 & 7 & 8 & $43.2(36.2)$ & $34.4(34.5)$ \\
\hline Waiting & 20 & 17 & 13 & 20 & 23 & 13 & 30 & 37 & 20 & 40 & 15 & 22 & 37.1(7.4) & $46.0(16.8)$ \\
\hline Total & 177 & 265 & 129 & 200 & 187 & 275 & 104 & 286 & 183 & 309 & 122 & 231 & 277 & 480 \\
\hline
\end{tabular}

$* \mathrm{~F}=$ Frequency, $\mathrm{T}=$ Time, $\mathrm{SD}:$ Standard Deviation

Table 5. Distribution(\%) of work posture

\begin{tabular}{|c|c|c|c|c|c|c|c|c|}
\hline \multicolumn{2}{|c|}{ Upper extremity } & Neutral & \multicolumn{2}{|c|}{ Bending } & Twisting & Bending \& Twisting & Invisible & Total \\
\hline \multicolumn{2}{|l|}{ Neck } & 31 & \multicolumn{2}{|c|}{55} & 4 & 8 & 2 & 100 \\
\hline \multirow{2}{*}{ Upper arm } & Left & 56 & 43 & 0 & - & - & 1 & 100 \\
\hline & Right & 48 & 48 & 2 & - & - & 2 & 100 \\
\hline \multirow{2}{*}{ Lower arm } & Left & 22 & \multicolumn{2}{|c|}{77} & - & - & 1 & 100 \\
\hline & Right & 22 & \multicolumn{2}{|c|}{78} & - & - & 0 & 100 \\
\hline \multirow{2}{*}{ Hand } & Left & 41 & \multicolumn{2}{|c|}{57} & - & - & 2 & 100 \\
\hline & Right & 29 & \multicolumn{2}{|c|}{69} & - & - & 2 & 100 \\
\hline \multicolumn{2}{|l|}{ Trunk } & 41 & 42 & 14 & 1 & 2 & 1 & 100 \\
\hline \multirow{2}{*}{\multicolumn{2}{|c|}{ Lower extremity }} & Standing & $\begin{array}{l}\text { Standing with } \\
\text { bending knee }\end{array}$ & Walking & Sitting & Etc. & Invisible & \\
\hline & & 47 & 4 & 47 & 1 & 1 & - & 100 \\
\hline
\end{tabular}

*Upper arm $90^{\circ}$, Trunk $45^{\circ}$

시간 비율) 을 나타낸 것이다. 건물청소직 작업자 각 체절의 비율과 일일 근무시간 중 발생 시간을 분석해 본 결과, 하루 8시간 작업 중 목 $(55 \%)$, 아래팔(좌: $77 \%$, 우: $78 \%$ ), 손 (좌: $57 \%$, 우: $69 \%$ )의 구부림이 가장 높은 비율을 나타냈 다. 하지의 경우 걷기 $(47 \%)$ 와 서기 $(47 \%)$ 가 총 작업시간의 $94 \%$ 를 차지하였다.

단위 작업별 자세분석 결과는 Table 6 과 같이 나타낼 수 있다. 빗자루 청소 작업의 구부림 비율은 목 $45 \%$, 좌측 아 래팔 $60 \%$, 우측 아래팔 $80 \%$ 로 구부림 비율이 높게 나타 났다. 허리의 경우 $45^{\circ}$ 이상의 구부림 자세가 $41 \%$ 를 나타 냈다. 하지는 서기 자세가 $72 \%$ 그리고 걷기 자세가 $28 \%$ 를 나타냈다. 물걸레질은 상체의 모든 부위에서 구부림 비
율이 높게 나타났으며, 하지는 서기가 $72 \%$ 를 나타냈다. 기 름걸레질 작업도 물걸레질과 마찬가지로 상체의 모든 부위 에서 구부림 비율이 높게 나타났으며, 하지는 걷기 자세가 $85 \%$ 를 나타냈다. 쓰레기 비우기 작업의 자세분석 결과 손 부위를 제외한 상체 부위에서 구부림 비율이 높게 나타났으 며, 허리는 $45^{\circ}$ 이상의 구부림 비율이 $43 \%$ 를 차지하였다. 하지는 서기 자세가 $75 \%$ 의 비율을 나타냈다. 쓰레기 버리 기 작업은 상체의 구부림 비율은 높지 않았으며, 하지는 걷 기 자세가 $76 \%$ 를 나타냈다. 닦기 작업의 자세분석 결과, 목 $46 \%$, 오른쪽 위팔 $71 \%$, 아래팔(좌: $85 \%$, 우: 94), 오른손 $87 \%$ 에서 구부림 비율이 높게 나타났으며, 허리는 중립 자 세의 비율이 높게 나타났다. 하지는 서기 자세가 $68 \%$ 를 차 
Table 6. The most Common postures for each task $(\%)$

\begin{tabular}{l|c|c|c|c|c|c|c|c|c}
\hline $\begin{array}{l}\text { Segment } \\
\text { \& Time }\end{array}$ & Sweeping & $\begin{array}{c}\text { Mopping } \\
\text { (Wet) }\end{array}$ & $\begin{array}{c}\text { Mopping } \\
\text { (Oil) }\end{array}$ & $\begin{array}{c}\text { Dumping } \\
\text { Trash Bags }\end{array}$ & $\begin{array}{c}\text { Moving } \\
\text { barrels/carts }\end{array}$ & Scrubbing & $\begin{array}{c}\text { Arrangement of } \\
\text { cleaning tool }\end{array}$ & $\begin{array}{c}\text { Arrangement } \\
\text { circumferential }\end{array}$ & $\begin{array}{c}\text { Moving of } \\
\text { cleaning tool }\end{array}$ \\
\hline $\mathrm{N}$ & Bending & Bending & Bending & Bending & Neutral & Bending & Bending & Bending & Bending \\
Time & 45 & 54 & 56 & 51 & 83 & 46 & 48 & 49 & 48 \\
LUA & Neutral & Bending & Bending & Bending & Neutral & Neutral & Bending & Neutral & Bending \\
Time & 78 & 62 & 57 & 57 & 67 & 58 & 69 & 46 & 69 \\
RUA & Bending & Bending & Bending & Bending & Neutral & Bending & Neutral & Bending & Neutral \\
Time & 49 & 73 & 65 & 64 & 71 & 71 & 55 & 54 & 55 \\
LLA & Bending & Bending & Bending & Bending & Neutral & Bending & Neutral & Bending & Neutral \\
Time & 60 & 89 & 79 & 73 & 56 & 85 & 58 & 93 & 58 \\
RLA & Bending & Bending & Bending & Bending & Neutral & Bending & Neutral & Bending & Neutral \\
Time & 80 & 97 & 90 & 68 & 66 & 94 & 85 & 88 & 85 \\
LH & Neutral & Bending & Neutral & Neutral & Neutral & Neutral & Neutral & Bending & Neutral \\
Time & 85 & 49 & 48 & 56 & 64 & 64 & 54 & 61 & 54 \\
RH & Bending & Bending & Bending & Neutral & Neutral & Bending & Neutral/Bending & Bending & Neutral/Bending \\
Time & 55 & 65 & 75 & 59 & 68 & 87 & 50 & 73 & 50 \\
T & Severe & Bending & Bending & Severe & Neutral & Neutral & Neutral & Neutral & Neutral \\
Time & bending & 41 & 73 & 48 & 43 & 89 & 44 & 54 & 73 \\
\hline Lower & Standing & Standing & Walking & Standing & Walking & Standing & Walking & Standing & Walking \\
Time & 72 & 72 & 85 & 75 & 76 & 68 & 89 & 87 & 89 \\
\hline
\end{tabular}

$* \mathrm{~N}=$ Neck; LUA = Left upper arm; RUA = Right upper arm; LLA = Left lower arm; RLA = Right lower arm; LH = Left hand; RH = Right hand; $\mathrm{T}=$ Trunk

지하였다. 청소도구 정리 작업은 허리와 왼쪽 위팔을 제외한 상체 부위에서 구부림 자세의 비율이 높게 나타났다. 하지는 걷기 자세가 $89 \%$ 를 차지하였다. 주변 정리 작업의 자세분 석 결과, 목 $49 \%$, 오른쪽 위팔 $54 \%$, 아래팔(좌: $93 \%$, 우: $88 \%$ ), 손(좌: $61 \%$, 우: $73 \%$ )에서 구부림 비율이 높게 나 타났으며, 허리는 중립 자세가 높은 비율을 차지하였다. 하 지는 서기 $87 \%$ 를 나타냈다. 청소도구 운반 작업은 목 $48 \%$, 왼쪽 위팔 $69 \%$ 에서 구부림 자세가 높게 나타났으며 허리는 중립 자세가 $54 \%$ 를 나타냈다. 하지는 걷기 자세가 $89 \%$ 를 나타냈다.

\section{Discussion}

건물청소직 작업자들은 주로 빗자루, 쓰레받기, 물걸레 등 의 작업도구를 사용하여 서기와 걷기 자세를 반복하여 쓰레 기를 청소하는 작업이다. 이 작업은 정적 근육 부하(허리의 굽힘과 비틀림) 와 어깨의 반복적인 움직임, 손과 손목에 강 한 힘을 요구한다(Hagner and Hagberg, 1989; Hopsu et al., 1994; Sogaard et al., 1996).

Nielsen(1995)은 1,166 명의 여성 건물청소직 작업자를 대상으로 한 연구에서 불편도는 목 $63 \%$, 어깨의 반복사용 으로 인해 $63 \%$, 허리 $36 \%$, 팔꿈치 $27 \%$, 손목 $46 \%$ 로 보 고하였다. 1997 2001년 동안 스웨덴에서 근무하는 건물청 소직 작업자를 대상으로 한 연구에서는 어깨와 손에 고통과 불편함이 $51 \%$ 를 차지하였으며, 사지는 $43 \%$, 등 $46 \%$, 허 리 $39 \%$ 로 보고하였다(Kumar and Kumar, 2008). USDL (2005)의 조사에 의하면 건물청소직 작업자는 허리의 문제 에 대해서 일반적으로 언급한다고 보고하였다.

청소 작업 중 허리와 팔은 상당시간을 정적 또는 부적절한 구부림 자세를 취한다(Hopsu et al., 1994). 또 이들은 한 쪽 혹은 양쪽 팔이 작업시간의 24 43\%가 어깨 높이 위의 자세를 취한다고 하고, 작업시간의 $3 \%$ 에서 $14 \%$ 는 쪼그리 고 앉는(Squatting) 자세를 유발한다고 하였다. Sogaard et al.(1996)의 연구에서는 자루걸레질 (Mopping) 동안 허리의 각도는 평균 $28^{\circ}$, 목은 $51^{\circ}$ 를 유지한다고 하였다. Nordin et al.(1986)의 연구에서는 자루걸레질 동안 허리에 구부림 자세가 유발된다고 하였다. 본 연구의 자세분석 결과에서도 목, 아래팔, 손, 허리의 구부림 비율이 높게 나타났다. 빗자 
루 청소, 물/기름걸레질, 쓰레기 버리기 작업은 바닥의 쓰레 기를 치우고 정리하는 작업이 상당수 차지하기 때문에 목, 허리, 팔의 구부림이 높은 비율로 나타나며, 보행 중 작업이 다수 발생한다. 부가적으로 신체 부위의 좌우를 비교하면 오 른쪽 위팔, 아래팔, 손 부위가 왼쪽에 비하여 약간 높은 구부 림 비율이 나타났다. 이는 조사 대상 작업자들은 오른손잡이 로서 오른손을 주로 사용하여 빗자루 청소, 닦기, 주변 정리 등의 작업을 실시하기 때문인 것으로 여겨진다.

Hopsu et al. (2000)은 건물청소직 작업의 $80 \%$ 는 손으로 하는 작업이며, 작업시간의 $30 \%$ 를 자루걸레질 (Mopping) 에 소비한다고 하였다. 본 연구 결과 또한 물걸레질과 기름 걸레질이 전체 작업시간 중 $30 \%$ 를 차지하여 같은 결과를 나타냈다. 자루걸레질 작업은 손목의 조절과 높은 근육 힘을 필요로 한다(Kumar and Kumar, 2008). 또한 반복적인 자루걸레질(Moppinjg)은 위팔(Upper arm) 과 허리(Back) 근육에 높은 정적 부하를 유발한다(Hagner and Hagberg, 1989). Hopsu et al. (2000) 과 Louhevaara et al. (2000) 은 자루걸레질이 근육의 부하와 심폐(Cardiorespiratory) 의 상승 원인이라고 하였다.

건물청소직 작업자들에게 일괄적으로 지급되는 청소도구 들은 작업자의 신체특성을 고려하지 않은 도구들이 많았다. 빗자루 청소 시에 사용되는 빗자루와 쓰레받기의 총 길이는 각각 $86 \mathrm{~cm}, 67 \mathrm{~cm}$ 로서 작업자가 도구를 사용하려면 불가피 하게 허리의 구부림 자세 $(71 \%)$ 가 발생하게 된다. 또한 기 름걸레질 작업에서 사용되는 도구인 기름걸레는 여성 작업 자가 다루기에는 다소 무거운 무게 $(4.3 \mathrm{~kg})$ 였다. Kruger et al. (1997)의 연구에서도 건물청소직 작업자의 도구는 작업 을 함에 있어서 노력을 최소화 할 수 있도록 디자인 되어 있 지 않다고 하였다. Woods and Buckle's(2005) 역시 건물 청소직 작업자가 사용하는 도구는 인간공학적 요인이 전혀 반영되지 않았다고 하였다.

건물청소직의 단위 작업들은 모두 구부림이 다수 발생하 는 부적절한 자세의 고반복을 요하는 작업들이기 때문에 작 업자들은 근골격계질환 발생이 쉬운 작업환경에 노출되어 있다. 이러한 환경에서 작업 부하를 최대한 감소시키기 위하 여 작업자들의 신체특성(키, 팔길이, 허리높이)을 반영할 수 있도록 조절식으로 설계된 인간공학적 청소 작업도구의 보 급이 필요하다. 비와 쓰레받기의 길이를 조절하여 과도한 허리 굽힘을 예방하고 꺾인 손잡이를 제공하여 손목의 구부 림을 방지해야 할 것이다. 물/기름걸레의 무게를 가능한 경 량화 해야 할 것이며, 선택적으로 여러 크기의 자루를 사용 해야 할 것이다. Kumar et al. (2005)는 인간공학적으로 디 자인된 자루걸레를 사용하면, 부하와 부적절한 자세를 방지 하는데 도움이 된다고 하였다. Messing et al.(1992)은 인 간공학적으로 디자인된 조절식 솔은 자세와 이동에 더 도움
이 된다고 하였으며, 짧은 핸들의 비(Broom)는 긴 핸들보 다 허리의 L5-S1에 더 큰 힘이 유발된다고 하였다.

본 연구는 근골격계질환 발생률이 높은 건물청소직 작업 자를 대상으로 인간공학적 평가 방법을 사용하여 작업을 평 가하였다. 연구의 제한점은 특정 장소의 작업자를 대상으로 현장 조사를 실시한 점과 연구대상의 수가 다수 부족하다는 것이 미흡한 점으로 판단된다. 자세분석의 경우 인접 체절 간에 발생하는 상호적인 특성을 고려하지 못했다. 추후 이러 한 단점을 반영한 자세 분류표의 개선이 필요할 것이다. 또 한 보다 객관적인 데이터 확보를 위해 전체 작업시간(8시 간)을 촬영하려 하였으나, 현장의 상황과 작업자의 사정으로 인하여 원활히 이루어 지지 않은 점이 제한점으로 남는다.

향후 진행되어야 할 연구로는 건물청소직 외의 서비스 업 종에 대하여 인간공학적인 평가가 이루어져야 할 것으로 예 상된다. 또한 실질적인 개선을 위하여 인간공학적으로 개선 된 도구 개발 및 작업 방법에 대한 연구를 진행해야 할 것 이다.

\section{References}

Korea Ministry of Labor, The statistic of industrial accidents state, 2004-2008.

Myong, J. P., Lee, H. K, Kim, H. R., Jeong, H. S., Jeong, E. H., Nam, W. and $\mathrm{K}, \mathrm{J}-\mathrm{W}$., Musculo-skeletal systems municipal sanitation workers and ergonomic evaluation on upperlimb, Korea Journal of Occupational Environment Medicine, 20(2), 93-103, 2008.

Park, K. H. and Jeong, B. Y., Study about the characteristics of old worker' musculoskeletal systems, Proceedings of the Ergonomics Society of Korea Conference, pp. 215-218. 2008.

Lee, I-S., Chung, M-K. and Kee, D-H., Evaluation of postural load of varying leg postures using the psychophysical scaling, Journal of the Ergonomics Society of Korea, 21(4), 47-65, 2002.

Lee, H. K., Myong, J. P., Jeong, E. H., Jeong, H. S. and Koo, J-W., Ergonomic workload evaluation and musculo-skeletal symptomatic features of street cleaners, Journal of the Ergonomics Society of Korea, 26(4), 147-152, 2007.

Korea Employment Information Service, The major job occupational of old worker, 2004.

Andrewa, D. M. and Callaghan, J. P., Determining the minimum sampling rate needed to accurately quantify cumulative spine loading from digitized video, Applied Ergonomics, 34(6), 589-595, 2003.

Baty, D. and Stubbs, D. S., Postural stress in geriatric nursing, International Journal of Nursing Studies, 24(4), 339-344, 1987.

Foreman, T. K. and Troup, J. D. G., Diurnal variations in spinal loading and the effects on stature: A preliminary study of nursing activities, Clinical Biomechanics, 2(1), 48-54, 1987. 
Genaidy, A. M., Guo, L., Eckart, R. and Troup, J. D. G., A postural stress analysis system for evaluating body movements and positions in industry, Proceedings of the Ergonomics Society Conference, Edinburgh, Scotland, pp. 346-351, 1993.

Grandgean, E. and Hunting, W., Ergonomics of posture-Review of various problems of standing and sitting posture, Applied Ergonomics, 8(3), 135-140, 1977.

Hagner, I. M. and Hagberg, M., Evaluation of two floor-mopping work methods by measurement of load, Ergonomics, 32(4), 401-408, 1989.

Hopsu, L., Louhevaara, V., Korhonen, O., Miettinen, M., Huikko, K., Lehtonen, T. and Wilkman, A., Feasibility and effects of the intervention for developing work organisation on stress and strain in professional cleaning, Rakennushallitus, Report 3, 1994.

Hopsu, L., Toivonen, Louhevaara, V. and Sjøgaard, K., Muscular strain during floor mopping with different cleaning methods. Proceedings of the XIV Triennial Congress of the International Ergonomics Association and the 44th Annual Meeting of the Human Factors and Ergonomics Society, San Diego, CA, USA, 29 July-4 August 2000, vol. 5. Human Factors and Ergonomics Society, Santa Monica, CA, USA, pp. 521-523, 2000.

Huth, E., Kruger, D. and Zorzi, G., 1996. Gesundheitsforderung im Krankenhausbetrieb, Funktionsbereich Reinigung. Abschlubericht, Fachhochschule Hamburg 5, Germany.

Johansson, S. E. and Ljunggren, G., Perceived exertion during a self imposed pace of work for a group of cleaners, Applied Ergonomics, 20(4), 307-312, 1989.

Karhu, O., Kansi, P. and Kuorinka, I., Correcting working postures in industry: a practical method for analysis, Applied Ergonomics, 8(4), 199-201, 1977.

Keyserling, W. M., Postural analysis of trunk and shoulders in simulated real time, Ergonomics, 29(4), 569-583, 1986.

Keyserling, W. M., Computer-aied posture analysis of the trunk, neck, shoulders and lower extremities, Taylor \& Francis, London, 1990.

Keyserling, W. M., Brouwer, M. and Silverstein, B. A., A checklist for evaluation ergonomic risk factors resulting from awkward postures of the legs, trunk and neck, International Journal of Industrial Ergonomics, 9(4), 283-301, 1992.

Kumar, R., Chaikumarn, M. and Kumar, S., Physiological, subjective and postural loads in passenger train wagon cleaning using a conventional and redesigned cleaning tool, International Journal of Industrial Ergonomics, 35(10), 931-938. 2005.

Kumar, R. and Kumar, S., Musculoskeletal risk factors in cleaning occupation-A literature review, International Journal of Industrial Ergonomics, 38(2), 158-170, 2008.

Kruger, D., Louhevaara, V., Nielsen, J. and Schneider, T., Risk assessment and Preventive Strategies in Cleaning Work. Wirtschaftsverl. NW, Verl. fur Neue Wiss, Bremerhaven, Germany, 1997.

Louhevaara, V., Hopsu, L. and Søgaard, K., Cardiorespiratory strain during floor mopping with different method, Proceedings of the XIV Triennial Congress of the International Ergonomics Association and the 44th Annual Meeting of the Human Factors and Ergonomics Society, San Diego, CA, USA, 29 July-4 August 2000, vol. 5, Human
Factors and Ergonomics Society, Santa Monica, CA, pp. 518-520, 2000 .

Messing, K., Haentjens, C. and Doniol-Shaw, G., Invisible and essential: work activity of women who clean bathrooms in French passenger trains, In: $25^{\text {th }}$ Annual Conference of the Human Factors Association of Canada, pp. 213-219. 1992.

Nielsen, J., Occupational health among cleaners. University of Copenhagen, National Institute of Occupational Health, Copenhagen, Denmark, 1995.

Nordin, M., Hultman, G., Philipsson, R., Ortelius, S. and Andersson, G. B. J., Dynamic measurements of trunk movements during work tasks. In: Corlett, N., Wilson, J., Manenica, I. (Eds.), The Ergonomics of Working Postures. Taylor\& Francis, Philadelphia, 1986.

Ryan, G. A., The prevalence of musculo-skeletal symptoms in supermarket workers, Ergonomics, 32(4), 359-371, 1989.

Søgaard, K., Fallentin, N. and Nielsen, J., Workload during floor cleaning. The effect of cleaning methods and work technique, European Journal of Applied Physiology, 73(1-2), 73-81, 1996.

USDL (U.S. Department of Labor), Bureau of Labor Statistics, Occupational Outlook Handbook 2006-07 Edition (BLS Bulletin 2570). US Government Printing Office, Washington, DC, 2005.

WHO (World Health Organization), Aging and work capacity, Report of a WHO Expert Committee. WHO Technical Report Series 835, Geneva, Switzerland, 1993.

Woods, V. and Buckle, P., Musculoskeletal ill health amongst cleaners and recommendations for work organisational change, International Journal of Industrial Ergonomics, 36(1), 61-72, 2005.

\section{Author listings}

Kyung-Sun Lee: 1ks79s@ajou.ac.kr

Highest degree: M.S., Department of Industrial and Information Systems Engineering, Ajou University

Position title: PhD. Candidate, Department of Industrial and Information Systems Engineering, Ajou University

Areas of interest: Ergonomics, Hand Biomechanics, Work Design

Inseok Lee: lis@hknu.ac.kr

Highest degree: Ph.D., Department of Industrial Engineering, POSTECH Position title: Professor, Department of Safety Engineering, Hankyong National University

Areas of interest: Ergonomics in Safety and Health, Agricultural Ergonomics, Accessible Design 
Hyunjoo Kim: kuffs@dku.edu

Highest degree: $\mathrm{PhD}$, Department of preventive medicine, Hanyang University

Position title: Associated professor, Department of occupational and environmental medicine, Dankook University

Areas of interest: Musculoskeletal disorders

Kyunghee Jung-Choi: jungchoikh@gmail.com

Highest degree: M.D., PhD., Department of Preventive Medicine, Ulsan

University

Position title: Assistant Professor, Department of Preventive Medicine,

Ewha Womans University School of Medicine

Areas of interest: Health inequalities, work-related disease

Jinwook Bahk: azrael@snu.ac.kr

Highest degree: MPH, Department of Occupational \& Environmental

Health, School of Public Health, Seoul National University

Position title: $\mathrm{PhD}$. Candidate, Department of Occupational \&

Environmental Health, School of Public Health, Seoul National University

Areas of interest: Ergonomics, Job stress, Health inequity
Myung-Chul Jung: mcjung@ajou.ac.kr

Highest degree: Ph.D., Department of Industrial Engineering, Pennsylvania State University

Position title: Associate Professor, Department of Industrial and Information Systems Engineering, Ajou University

Areas of interest: Work design, ergonomics, product development

Date Received : 2011-03-28

Date Revised :2011-05-24

Date Accepted : 2011-05-28 